\title{
Increasing pechay (Brassica rapa L. ssp. chinensis) production through suitable seedling establishment under two cultivation systems in the Southern Philippines
}

\author{
Zenaida C. Gonzaga ${ }^{1 *}$, Othello B. Capuno', Marina A. Labonite ${ }^{2}$, Eugenia de Asis \\ Lonzaga ${ }^{3}$, Nemisio Francisco M. Napuran ${ }^{3}$, Aiselyn A. Sarco', Ana Linda G. \\ Gorme', Jessie C. Rom', Hubert B. Dimabuyu', Dennis B. Jomoc' ${ }^{2}$, Julie Carme \\ G. Estillore ${ }^{2}$, Abegail B. Sentorias ${ }^{2}$, J. Villanueva ${ }^{3}$, Adam D. Goldwater ${ }^{4}$, Gordon \\ S. Rogers ${ }^{4}$ and Sandra McDougall ${ }^{5}$
}

\begin{abstract}
Seedling management is very important in leafy vegetable with short period of growing as it covers almost half of the production period. Pechay is considered a high value and a highly demanded leaf vegetable in the Philippines. These studies were conducted to determine the best method of raising pechay seedlings including direct seeding, seed box and seedling tray under two cultivation systems in different provinces of southern Philippines namely Bohol, Leyte and Samar. The studies were conducted in each province and data were consolidated and combined. Protected cultivation slightly manifested benefits on survival, root characteristics and yield except in Bohol where 3 times fold yield of plants under protective structure than open field. There was better survival and yield of using seedling tray. The unfavorable method was seed box in Bohol and Leyte while direct seeding in Samar as evident by low survival and yield. Among the three provinces in southern Philippines, Leyte produced the highest yield of pechay per unit area. This suggests that no similar method of raising seedlings was effective in different parts of southern Philippines.
\end{abstract}

Keywords: Brassicaceae, clod seedling, bare-root, low tunnel, net cover, leafy vegetable

\section{INTRODUCTION}

Pechay (Brassica rapa L. ssp. chinensis) is considered the most consumed

\footnotetext{
${ }^{1}$ Visayas State University (VSU), Philippines

${ }^{2}$ Bohol Island State University (BISU), Philippines

${ }^{3}$ Northwestern Samar State University (NwSSU), Philippines

${ }^{4}$ Applied Horticultural Research (AHR), Australia

${ }^{5}$ Department of Primary Industries (DPI), Australia

* Corresponding Author. Address: Department of Horticulture, Visayas State University, Visca, Baybay City, Leyte,6521-A Philippines; E-mail:zcgonzaga@yahoo.com Dol: $10.32945 /$ atr39sb10.2017
} 
leafy vegetable in the Philippines and contributes a very good income provider for farmers due to its short duration harvesting. This crop can be harvested $30-45$ days from planting (Siemonsma \& Piluek 1994). Seedling foundation of this crop strongly affects performance as it contributes to almost half of the duration in cropping.

Most vegetable crop are highly influenced on how the seedlings are produced. There are so many methods of raising seedlings which includes direct seeding, seed box, and seedling tray method. The seed box and seedling tray methods are those that requires transplanting. The advantages and disadvantages of each method were not well documented on pechay production.

Many farmers in the southern Philippines used direct seeding in planting pechay. However, farmers often encountered problems on germination due to the small size seeds which made them prone to be washed out during heavy rains. Seedlings too are easily damaged by insect pest and diseases. The knowledge on seedling technology are not yet disseminated such that meticulous farmers lack evidence to change from their comfort zone of practice which are ineffective. Among the mentioned method of raising seedlings, no study was conducted in southern Philippines as basis for better performance of the crop in each province.

Protected cropping on vegetable production was believed to be economically feasible and results of research in Visayas State University on open field cultivation showed negative correlation of rainfall and vegetable productivity (Gonzaga et al 2013, Capuno et al 2015). Some parts of southern Philippines doesn't have the technology of protected cropping such as Bohol and Samar. Hence, this study aimed to evaluate the performance of pechay in the three provinces grown in protected cropping and open field.

\section{MATERIALS AND METHODS}

\section{Site Description}

These studies were conducted in the Australian Centre for International Agricultural Research-Integrated Crop Management (ACIAR-ICM) project site of Bohol Island State University (BISU) in Bohol, Northwest Samar State University (NwSSU) in Samar, and Visayas State University (VSU) in Leyte of the southern Philippines. Each location were all situated inside the university perimeter.

\section{Protective Structure}

The low tunnels protective structure covered with \#50 mesh UV treated net were used in the three sites. Each tunnel had a length of $10 \mathrm{~m}$ that accommodated the three treatments in one replicate. The frame of tunnel was made of flexible iron bars which stand $1 \mathrm{~m}$ in height and distance between ends.

\section{Experimental Design}

Each experiment from specific site was laid out in randomized complete block design with 3 replications. Combined analysis from different sites was carried out in factorial design with 3 factors. The main plot was different sites (provinces), sub- 
Increasing pechay

plot was type of cultivation (open field \& protective structure) and sub-sub-plot was methods of raising seedlings.

\section{Treatments}

Three methods of raising seedling were used in the study such as direct seeding, seed box and seedling tray and were established in open field and protective structure. The direct seeding (T1) method was done by sowing the seeds directly into the field simultaneous with the sowing of seeds in seed box. There were 3 seeds sown each hill and thinned to 1 seedling after 3 days of germination leaving the most vigorous. For seed box (T2) method, the seeds were sown in seed box made of styrofoam measuring $52.07 \mathrm{~cm}$ long, $34.72 \mathrm{~cm}$ wide, and $9.86 \mathrm{~cm}$ depth filled with medium containing 2 parts garden soil, 1 part vermicast and 1 part carbonized rice hull by volume. Three days after germination, seedlings were transplanted into the field and remaining seedlings were pricked to individual plug of seedling tray for the seedling tray method (T3). The medium used in seedling tray was similar in seed box. The size of plug in seedling tray measured $32 \mathrm{~mm}$ diameter, $32 \mathrm{~mm}$ depth, and has 128 holes in a tray. The seedling tray (T3) method was transplanted into the field after 12 days in nursery which included hardening of 3 days. The planting distance of plants in the field by all methods was $20 \mathrm{~cm} \times 20 \mathrm{~cm}$ in triangular planting.

\section{Fertilization and Irrigation}

Each plant were fertilized with $10 \mathrm{~g}$ complete fertilizer (16-16-16 NPK) at planting and weekly drenching of $150 \mathrm{~mL}$ of calcium nitrate $\left(19 \% \mathrm{Ca} \& 15.5 \% \mathrm{NO}_{3}\right)$ solution at a concentration of $250 \mathrm{~g}$ per $50 \mathrm{~L}$ water. Basal fertilization included application of $100 \mathrm{~g}$ carbonized rice hull for enhancing fertilizer adsorption. The plants were irrigated using J-turbo slim drip irrigation system which dispenses approximately $1.2 \mathrm{~L}$ per hour.

\section{Data Analysis}

Data gathered were analyzed by Analysis of variance (ANOVA) using Statistical Tool for Agricultural Research (STAR) software version 2.0.1 developed by International Rice Research Institute (IRRI) biometrics group. The means were compared by least significant difference (LSD) at $1 \%$ level of significance.

\section{RESULTS AND DISCUSSION}

\section{Survival}

The survival of pechay plants was significantly influenced by method of raising seedlings with different results from each provinces (Table 1). There were disadvantageous effect of seed box method in Bohol and Leyte whereas direct seeding in Samar. Differences of results from all provinces growing were due to weather conditions that varied during transplanting/sowing period.There was sunny hot days during transplanting from seed box in Bohol and Leyte which added 
stress to the seedlings. In seed box method, the seedlings were very much stressed as they were removed from seed box bare rooted. As reported, root damage during removal of the seedlings from their growing medium provides major risk in the preparation of bare-root planting materials (Himelick \& Watson 1990). Samar had better survival from seed box than direct seeding as rain during transplanting helped the seedlings minimized wilting and rain on direct seeding splashed the seeds away and were carried by run-offs. Although direct seeding under protected cropping avoided splashing of seeds, the decrease of germination was due to strong run-offs that brought the seeds out place as rain penetrates the net covering. Seedling tray method consistently resulted to best survival among all sites. The use of seedling tray method clearly showed the benefit for pechay production that enhance seedling survival on field. Seedlings in this method were larger enough to compensate insect damage, adverse environmental condition and little influence of stress by transplanting as root systems were slightly disturbed due to protection by clod of soil intact. This suggests that seedling tray method was best method of raising seedlings for best survival especially in areas with unpredicted weather conditions like in southern Philippines.

Table 1. Survival (\%) of pechay gathered from different province of southern Philippines grown in low tunnel protective structure and open field with different methods of raising seedlings

\begin{tabular}{llcc}
\hline \multirow{2}{*}{$\begin{array}{l}\text { Cultivation/Method of raising } \\
\text { seedlings }\end{array}$} & \multicolumn{3}{c}{ \% survival } \\
\cline { 2 - 4 } & Bohol & Leyte & Samar \\
\hline Open field & 76.39 & 91.69 & 71.94 \\
Protected & 83.33 & 92.71 & 77.50 \\
& & & \\
Direct seeding & $80.00 \mathrm{ab}$ & $96.26 \mathrm{a}$ & $63.83 \mathrm{~b}$ \\
Seed box & $71.88 \mathrm{~b}$ & $81.51 \mathrm{~b}$ & $78.79 \mathrm{a}$ \\
Seedling tray & $87.71 \mathrm{a}$ & $98.84 \mathrm{a}$ & $81.55 \mathrm{a}$ \\
\hline
\end{tabular}

Means with the same and/or no letter designation within the same column in a block are not significantly different compared using least significant difference at $1 \%$ level of significance $(n=10)$

\section{Root Characteristics}

Root measurements differed significantly by method of raising seedlings but slightly similar in two cultivation systems (Table 2). The root system of seedlings from seed box method in Bohol and Leyte had significantly lower fresh weight and volume compared to seedling tray and direct seeding method. In Samar situation, there was no significant difference from the three methods of raising seedlings due to some inferior characteristics of plants in overall compared to other sites. Small plants have small root systems as result of plant proportions. The significant results in Bohol and Leyte were influenced by root stress during uprooting from seed box and transplanted that pruned some of the root hairs and even cut the tap root which made different from direct seeding and seedling tray method. The difference of results implies that there may be differences of handling of seedlings from seed box method prior to transplanting. 
Increasing pechay

Table 2. Root parameters of pechay gathered from different province of southern Philippines grown in low tunnel protective structure and open field with different methods of raising seedlings

\begin{tabular}{lllllllllll}
\hline Cultivation/ & \multicolumn{1}{c}{ Root (per plant) } \\
\cline { 2 - 11 } $\begin{array}{l}\text { Method of } \\
\text { raising }\end{array}$ & \multicolumn{3}{c}{ Fresh wt. (g) } & \multicolumn{3}{c}{ Dry wt. (g) } & \multicolumn{3}{c}{ Volume (cc) } \\
\cline { 2 - 11 } seedlings & Bohol & Leyte & Samar & Bohol & Leyte & Samar & Bohol & Leyte & Samar \\
\hline Open field & 8.01 & 12.10 & 4.54 & 1.35 & 1.31 & 0.82 & 7.07 & 8.64 & 5.89 \\
Protected & 7.47 & 14.13 & 4.57 & 1.04 & 1.52 & 0.56 & 6.95 & 9.76 & 5.64 \\
Direct & $8.02 \mathrm{ab}$ & $14.59 \mathrm{a}$ & $3.01 \mathrm{a}$ & $1.45 \mathrm{a}$ & $1.54 \mathrm{ab}$ & $0.24 \mathrm{~b}$ & $7.12 \mathrm{ab}$ & $10.40 \mathrm{a}$ & $4.33 \mathrm{a}$ \\
seeding & & & & & & & & & \\
Seed box & $5.96 \mathrm{~b}$ & $9.16 \mathrm{~b}$ & $5.26 \mathrm{a}$ & $0.99 \mathrm{a}$ & $1.06 \mathrm{~b}$ & $0.93 \mathrm{a}$ & $5.47 \mathrm{~b}$ & $6.17 \mathrm{~b}$ & $6.20 \mathrm{a}$ \\
Seedling tray & $9.24 \mathrm{a}$ & $15.59 \mathrm{a}$ & $5.40 \mathrm{a}$ & $1.14 \mathrm{a}$ & $1.64 \mathrm{a}$ & $0.90 \mathrm{a}$ & $8.45 \mathrm{a}$ & $11.03 \mathrm{a}$ & $6.77 \mathrm{a}$ \\
\hline
\end{tabular}

Means with the same and/or no letter designation within the same column in a block are not significantly different compared using least significant difference at $1 \%$ level of significance $(n=10)$

\section{Yield and Yield Components}

The weight of marketable (Table 3) and total yield (Table 5) of pechay in Bohol was significantly affected by type of cultivation imposed on the crop in which the yield under protected cropping increased by almost 3 times than open field cultivation. The increase of yield in Bohol was due to lesser disturbance from heavy rainfall than the open field which heavy droplets of rain caused soil splash into the leaf surface that covered photosynthetic parts of the plant. Similarly, the weight of non-marketable pechay in Leyte was significantly increased in protected cropping due to pest and disease incidence (Table 4). This implies that the utilization of protective structure was beneficial especially in Bohol during that time of cropping and in Samar and Leyte where favorable condition of cropping, the protective structure didn't manifest benefit.

Method of raising seedlings significantly affected number of marketable and non-marketable plants in Samar, weight of marketable and total yield in Bohol and Samar, and weight of non-marketable pechay in Leyte (Table 3, 4 \& 5). Few number of plants in Samar using direct seeding was due to strong rain as supported by low survival in Table 1. The seeds were carried by run-offs and/or some other factors like birds, ants, and unfavorable environment of seeds to germinate. The direct seeding in Bohol produced the highest yield and seedling tray method in Samar. The differences of results were mainly due to variation on weather especially on planting/transplanting condition. On the other hand, the effect of stress by uprooting from seed box in Bohol was often long lasting and may affect the subsequent yields as well as nutrient content in leaves at harvest (Daly \& Tomkins 1995, Kalisz \& Cebula 2001). The increase of non-marketable plants in Leyte was associated by insect damage and stunted plants which were undersized and therefore cannot be sold (Gonzales et al 1991). Unlike from seed box and seedling tray method, the seedlings exposed in the field were already bigger enough to compensate insect damage and other adverse conditions. Reported by Leskovar and Cantliffe (1993) and Nesmith et al (1998) that transplants yielded highest and early harvesting than the direct seeded plants. This suggests that weather condition and timing were important considerations in selection of method of raising seedlings and no similar effective method in each province of southern Philippines. 
Gonzaga et al

Table 3. Number and weight ( $\mathrm{kg}$ per $3 \mathrm{~m}^{2}$ ) of marketable pechay gathered from different province of southern Philippines grown in low tunnel protective structure and open field with different methods of raising seedlings

\begin{tabular}{lllllll}
\hline \multirow{2}{*}{$\begin{array}{l}\text { Cultivation/Method of } \\
\text { raising seedlings }\end{array}$} & \multicolumn{3}{c}{ Number of marketable plants } & \multicolumn{3}{c}{ Weight of marketable plants (kg per } \\
\cline { 2 - 7 } & Bohol & Leyte & Samar & Bohol & Leyte & Samar \\
\cline { 2 - 7 } & 30.00 & 44.00 & 36.83 & $1.68 \mathrm{~b}$ & $5.90 \mathrm{a}$ & $2.46 \mathrm{a}$ \\
Open field & 31.83 & 44.53 & 37.56 & $5.38 \mathrm{a}$ & $6.72 \mathrm{a}$ & $3.20 \mathrm{a}$ \\
Protected & $27.25 \mathrm{a}$ & $46.40 \mathrm{a}$ & $18.59 \mathrm{~b}$ & $4.67 \mathrm{a}$ & $6.47 \mathrm{a}$ & $0.80 \mathrm{c}$ \\
Direct seeding & $27.50 \mathrm{a}$ & $38.80 \mathrm{a}$ & $44.57 \mathrm{a}$ & $2.61 \mathrm{~b}$ & $5.85 \mathrm{a}$ & $2.97 \mathrm{~b}$ \\
Seed box & $38.00 \mathrm{a}$ & $47.60 \mathrm{a}$ & $48.43 \mathrm{a}$ & $3.30 \mathrm{ab}$ & $6.61 \mathrm{a}$ & $4.73 \mathrm{a}$ \\
Seedling tray & & & & &
\end{tabular}

Means with the same and/or no letter designation within the same column in a block are not significantly different compared using least significant difference at $1 \%$ level of significance $(n=10)$

Table 4. Number and weight $\left(\mathrm{kg}\right.$ per $\left.3 \mathrm{~m}^{2}\right)$ of non-marketable pechay gathered from different province of southern Philippines grown in low tunnel protective structure and open field with different methods of raising seedlings

\begin{tabular}{|c|c|c|c|c|c|c|}
\hline \multirow{2}{*}{$\begin{array}{l}\text { Cultivation/Method } \\
\text { of raising seedlings }\end{array}$} & \multicolumn{3}{|c|}{ Number of non-marketable plants $\left(3 \mathrm{~m}^{2}\right)$} & \multicolumn{3}{|c|}{$\begin{array}{l}\text { Weight of non-marketable plants }(\mathrm{kg} \\
\left.\text { per } 3 \mathrm{~m}^{2}\right)^{a}\end{array}$} \\
\hline & Bohol & Leyte & Samar & Bohol & Leyte & Samar \\
\hline Open field & 15.78 & 2.93 & 10.11 & $0.18 \mathrm{a}$ & $0.11 b$ & $0.41 \mathrm{a}$ \\
\hline Protected & 16.11 & 4.53 & 12.91 & $0.04 a$ & $0.45 a$ & $0.53 a$ \\
\hline Direct seeding & $17.67 a$ & $7.20 \mathrm{a}$ & $22.83 a$ & $0.21 \mathrm{a}$ & $0.60 \mathrm{a}$ & $0.65 a$ \\
\hline Seed box & $15.58 \mathrm{a}$ & $2.40 \mathrm{a}$ & $6.93 b$ & $0.06 a$ & $0.05 b$ & $0.37 a$ \\
\hline Seedling tray & $14.58 \mathrm{a}$ & $1.60 \mathrm{a}$ & $4.77 \mathrm{~b}$ & $0.06 \mathrm{a}$ & $0.19 \mathrm{~b}$ & $0.39 a$ \\
\hline
\end{tabular}

Means with the same and/or no letter designation within the same column in a block are not significantly different compared using least significant difference at $1 \%$ level of significance $(n=10)$

Note:

$$
{ }^{a} 5 \% \text { level of significance }
$$

Table 5. Total yield $\left(\mathrm{t} \mathrm{ha}^{-1}\right)$ of pechay gathered from different province of southern Philippines grown in low tunnel protective structure and open field with different methods of raising seedlings

\begin{tabular}{lccc}
\hline \multirow{2}{*}{$\begin{array}{l}\text { Cultivation/Method of raising } \\
\text { seedlings }\end{array}$} & \multicolumn{3}{c}{ Total Yield $\left(\mathrm{t} \mathrm{ha}^{-1}\right)$} \\
\cline { 2 - 4 } & Bohol & Leyte & Samar \\
\hline Open field & $6.19 \mathrm{~b}$ & $20.96 \mathrm{a}$ & $9.55 \mathrm{a}$ \\
Protected & $18.06 \mathrm{a}$ & $23.90 \mathrm{a}$ & $12.46 \mathrm{a}$ \\
Direct seeding & $16.28 \mathrm{a}$ & $21.75 \mathrm{a}$ & $4.81 \mathrm{~b}$ \\
Seed box & $8.90 \mathrm{~b}$ & $21.49 \mathrm{a}$ & $12.04 \mathrm{a}$ \\
Seedling tray & $11.19 \mathrm{ab}$ & $24.05 \mathrm{a}$ & $16.16 \mathrm{a}$ \\
\hline
\end{tabular}

Means with the same and/or no letter designation within the same column in a block are not significantly different compared using least significant difference at $1 \%$ level of significance $(n=10)$ 
Increasing pechay

\section{Comparison Among Sites}

There were significant difference of pechay measurements from different provinces of southern Philippines as shown in Table 6. Better measurements of pechay grown in Leyte on survival, root parameters, and yield and yield components. Weight of marketable and total yield from Leyte increased by almost 2 times fold than other sites. The increase in yield was due to better soil fertility which varies from among sites. Total yield was also contributed by the highest survival $(92.2 \%)$ and heaviest root fresh weight $(13.11 \mathrm{~g})$.

Table 6. Comparison of survival (\%), roots parameters, yield and yield components of Pechay from different provinces of southern Philippines

\begin{tabular}{|c|c|c|c|c|c|c|c|c|c|}
\hline \multirow{2}{*}{ Province } & \multirow{2}{*}{$\begin{array}{l}\text { Survival } \\
(\%)\end{array}$} & \multicolumn{3}{|c|}{ Root (per plant) } & \multicolumn{2}{|c|}{ Marketable yield } & \multicolumn{2}{|c|}{$\begin{array}{l}\text { Non-marketable } \\
\text { yield }\end{array}$} & \multirow[t]{2}{*}{$\begin{array}{c}\text { Total } \\
\text { yield } \\
\left(\mathrm{t} \mathrm{ha}^{-1}\right)\end{array}$} \\
\hline & & $\begin{array}{l}\text { Fresh } \\
\text { wt. (g) }\end{array}$ & $\begin{array}{c}\text { Dry } \\
\text { wt. (g) }\end{array}$ & $\begin{array}{l}\text { Volume } \\
\text { (cc) }\end{array}$ & Number & $\begin{array}{c}\text { Weight }(\mathrm{kg} \\
\left.\text { per } 3 \mathrm{~m}^{2}\right)\end{array}$ & Number & $\begin{array}{l}\text { Weight } \\
(\mathrm{kg} \mathrm{per} \\
\left.3 \mathrm{~m}^{2}\right)^{\mathrm{a}}\end{array}$ & \\
\hline Bohol & $79.86 b$ & $7.74 b$ & $1.20 \mathrm{a}$ & $7.01 \mathrm{~b}$ & $30.92 b$ & $3.53 b$ & $15.94 a$ & $0.11 b$ & $12.12 \mathrm{~b}$ \\
\hline Leyte & $92.20 \mathrm{a}$ & $13.11 \mathrm{a}$ & $1.41 \mathrm{a}$ & $9.20 \mathrm{a}$ & $44.27 a$ & $6.31 a$ & $3.73 b$ & $0.28 a b$ & $22.43 a$ \\
\hline Samar & $74.72 b$ & $4.55 c$ & $0.69 \mathrm{~b}$ & $5.77 c$ & $37.20 \mathrm{ab}$ & $2.83 \mathrm{c}$ & $11.51 \mathrm{a}$ & $0.47 a$ & $11.00 \mathrm{~b}$ \\
\hline
\end{tabular}

Means with the same and/or no letter designation within the same column in a block are not significantly different compared using least significant difference at $1 \%$ level of significance $(n=10)$ Note:

${ }^{a} 5 \%$ level of significance

The soil condition in Bohol at planting had a pH of 4.2, an $\mathrm{OM}$ of $2.6 \%$, and a phosphorous content of $20.3 \mathrm{ppm}$ while deficient in potassium based on the soil analysis tested by the City Agriculture Soil Analytical Lab in Cebu City. This condition of the soil was not very much favorable to pechay as $4.2 \mathrm{pH}$ was acidic. Availability of nutrients at acidic level of soil is inhibited for absorption by plant. Similarly, Samar condition had poor soil fertility. Although, there was no soil analysis many parts in Samar had marginal soil which were also acidic in composition.

\section{CONCLUSION}

These studies were conducted in southern Philippines to evaluate pechay production through different cultivation systems and methods of raising seedlings. Results have shown that the benefit of protective structure did not manifest on favorable conditions of the year in two provinces except in Bohol where there was heavy rainfall during the cropping that resulted to 3 times fold yield in protected cropping than open field. On the other hand, there was no similar method of raising seedlings which are effective in all provinces. Seedling tray method was effective in Leyte and Samar, and direct seeding in Bohol. Moreover, better pechay production can be produced in Leyte due to better soil condition. 
Gonzaga et al

\section{RECOMMENDATION}

Further work needs to be done to determine the potential of protective structure in all period of pechay production over the year. There must be continuous planting throughout the year as microclimate in different provinces in southern Philippines varies heterogeneously. More research is needed on method of raising seedlings in each of the province to verify the results of the studies. On the production of pechay, the findings showed that good soil fertility produce optimum production of the vegetable.

\section{REFERENCES}

Capuno OB, Gonzaga ZC, Loreto MB, Gerona RG, Borines LM, Tulin AB, Lusanta DC, Dimabuyu HB, Vega MLP, Mangmang JS \& Rogers GS. 2015. Development of a cost-effective protected vegetable cropping system in the Philippines. Acta Horticulturae 1107:221-228. doi:10.17660/ActaHortic.2015.1107.30

Daly $\mathrm{P}$ and Tomkins B. 1995. Production and postharvest handling of Chinese cabbage (Brassica rapa var. pekinensis) (pp41). RIRDC 97/1

Himelick EB and Watson GW. 1990. Reduction of oak chlorosis with wood chip mulch treatments. Journal of Arboriculture 16: 275-278

Gonzaga ZC, Capuno OB, Loreto MB, Gerona RG, Borines LM, Tulin AT, Mangmang JS, Lusanta DC, Dimabuyu HB \& Rogers GS. 2013. Low-cost protected cultivation: Enhancing year-round production of high value vegetables in the Philippines. In Oakeshott J and Hall D (eds) Smallholder HOPES-horticulture, people and soil (pp298). ACIAR

Gonzales JA, Diputado JR MT \& Briones ED. 1991. Effect of seedling production method and transplanting age on the field establishment, growth and yield of pechay (Brassica rapus var. chinensis). Philippine Journal of Crop Science 16(supplement1):57

Kalisz A and Cebula S. 2001. Direct plant covering and soil mulching in the Spring production of some chinese cabbage cultivars. Effect of temperature on premature bolting. Folia Horticulturae 13(1):13-22

Leskovar DI and Cantliffe DJ. 1993. Comparison of Plant Establishment Method, Transplant, or Direct Seeding on Growth and Yield of Bell Pepper. Journal of the American Society of Horticultural Science 118(1):17-22

Nesmith SD and Duval JR, 1998. Transplant Production and Performance: The effect of container size. HortTechnology 8(4):495-498. http://swfrec.ifas.ufl. edu/docs/pdf/veg-hort/transplant/trans_cs1.pdf

Siemonsma JS and Piluek K. 1994. Plant resources of South-East Asia. No. 8: Vegetables. Bogor:Prosea 